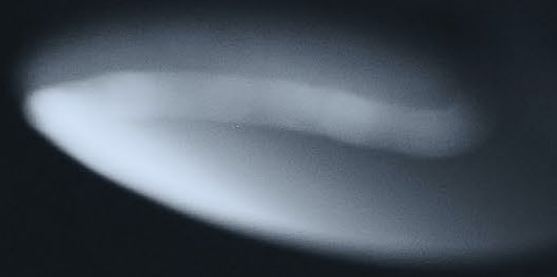

\title{
Finding Social Purpose in a Pandemic
}

Steve Doggett explains how Unilink made use of new research on the risk of suicide in custodial settings to develop a tool to support prison staff to identify people at risk of suicide and self-harm. 
As the Covid-19 pandemic began to spread through our society it created untold difficulties for those under the care of prisons and probation services. It arrived at a time when the UK Ministry of Justice were reporting self-harm levels in its prisons to be at a record high; an $11 \%$ increase on the previous 12 months and almost double the number of self-harm incidents compared to the same period in 2015 (Ministry of Justice, March 2020). Fazel \& Benning (2009) report that rates of suicide in UK prisons are higher than the general population reporting as much as 5 and 20 times higher among males and females respectively. Both self-harming and suicidal behaviours are significant and escalating problems in UK prisons.

With that backdrop, on 24th March 2020 the Secretary of State for Justice placed all prisons across England and Wales in an immediate lock down. The impact of the decision was that all prisoners faced restricted regimes; they were locked in cells for 23 hours of the day and social visits, work, education and gym activities were suspended. The concern was that these additional restrictions could deepen feelings of isolation in prisoners and exacerbate the problems of self-injurious and suicidal behaviour. Around the same time Favril et al.(2020) published a comprehensive meta-analysis in the Lancet that synthesised data from almost fifty years of research identifying five categories

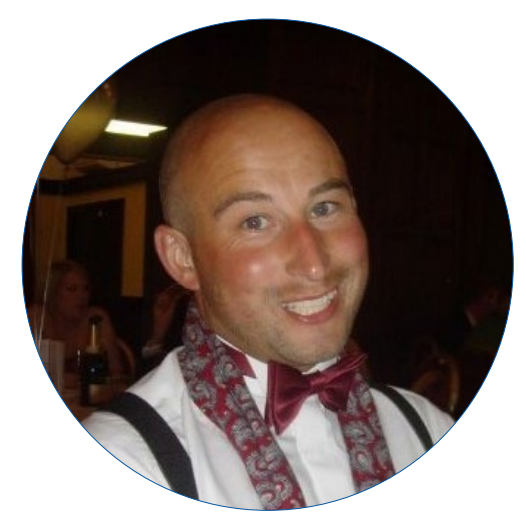

Steve Doggett

Systems Consultant - Probation Unilink grouping risk factors commonly associated with self-harm in prison. They identified strong effects for modifiable clinical and custodial factors, moderate effects for historical factors, and smaller effects for sociodemographic and criminological factors. 
As a technology partner of the MoJ, Unilink dealt with the pandemic by working with government and prison providers to analyse whether we could help solve any of these emerging problems. In this period Unilink committed to developing a solution to the suspension of prison visits and we successfully launched secure video calls technology in Scotland with the service offered free for three months as part of our commitment to social purpose. Reducing suicide and self-harm became a priority for Unilink and we built on previous work with the Samaritans to enable a two-way messaging service. Unilink undertook a series of user research discovery sessions that focused our team on custodial risk factors of isolation, employment, insecurity, lack of privacy, and forced solitary confinement (Metzner and Fellner 2010). These "pains of imprisonment" can be evidenced through prisoner transactions, or lack thereof, held on our prison systems. The decision was taken for Unilink to collaborate with our partner Serco to develop a web-based application that analyses patterns of behaviour and identifies individuals who may have increased vulnerability towards suicide or self-harm. The Vulnerability Predictor Tool (VPT) was developed from their proof of concept that analysed interactions processed by Unilink's Prisoner Self-Service Kiosks / In Cell Devices and held in Unilink's Custodial Management System (CMS) database.

\section{Vulnerability Predictor}

\begin{tabular}{|c|c|c|c|c|c|c|}
\hline \multicolumn{3}{|c|}{ Taroeted All 1} & \multirow[b]{2}{*}{ Arrived } & \multirow[b]{2}{*}{ Cell } & \multirow[b]{2}{*}{ - } & \multirow[b]{2}{*}{ Visits } \\
\hline (2) 1 & Inmate & & & & & \\
\hline \multirow[t]{14}{*}{ • } & Joshua Glass & & $8 \mathrm{yOm}$ & A2 -6 & $\odot$ & 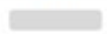 \\
\hline & Sean Butler & & $8 \mathrm{y}_{\mathrm{m}}$ & C1 $\cdot 17$ & & 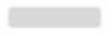 \\
\hline & Paul Duran & & $8 y 5 m$ & $\mathrm{C} 3 \cdot 21$ & & 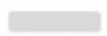 \\
\hline & John Thompson & & $8 y 4 m$ & & & 6 months \\
\hline & John Scott & & 8y $1 \mathrm{~m}$ & E1 13 & & 6 montes \\
\hline & Mathew Browning & & $8 \mathrm{y} 1 \mathrm{~m}$ & & & 6 months \\
\hline & Douglas Morrison & & $8 \mathrm{yOm}^{2} \mathrm{y}$ & & & 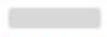 \\
\hline & Nathan Sims & & $8 y 6 \mathrm{~m}$ & & & 5 meds \\
\hline & Cameron Lee & & $8 y 5 m$ & & & 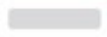 \\
\hline & Tony Dyer & & $7 y 2 \mathrm{~m}$ & D3 $\cdot 16$ & & 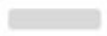 \\
\hline & David Mahoney & & $8 y 3 m$ & & & 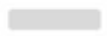 \\
\hline & Justin Allen & & $8 y 3 m$ & CSU2 $\cdot 10$ & & 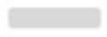 \\
\hline & Colin Bolton & & $8 y 2 m$ & & & 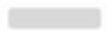 \\
\hline & Bradley Burns & & $8 y 2 m$ & B1. 6 & & 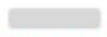 \\
\hline & Dakota Jones & & $8 \mathrm{y} 1 \mathrm{~m}$ & & $\odot$ & 6 monts \\
\hline & Bradley Obrien & & $8 y 1 \mathrm{~m}$ & & & 3 meds \\
\hline & Bradley Castro & & $8 \mathrm{y} 1 \mathrm{~m}$ & & & 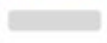 \\
\hline & John Patterson & & $8 y_{1 m}$ & & & 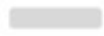 \\
\hline & Thomas Hughes & & $8 y 1 \mathrm{~m}$ & & & 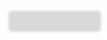 \\
\hline & Charles Lee & & $8 y 1 \mathrm{~m}$ & & & 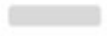 \\
\hline & Emest Brown & & $8 y 1 \mathrm{~m}$ & & & 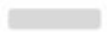 \\
\hline & Sean Lopez & & $7 y 1 m$ & $83 \cdot 12$ & $\odot$ & 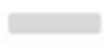 \\
\hline
\end{tabular}

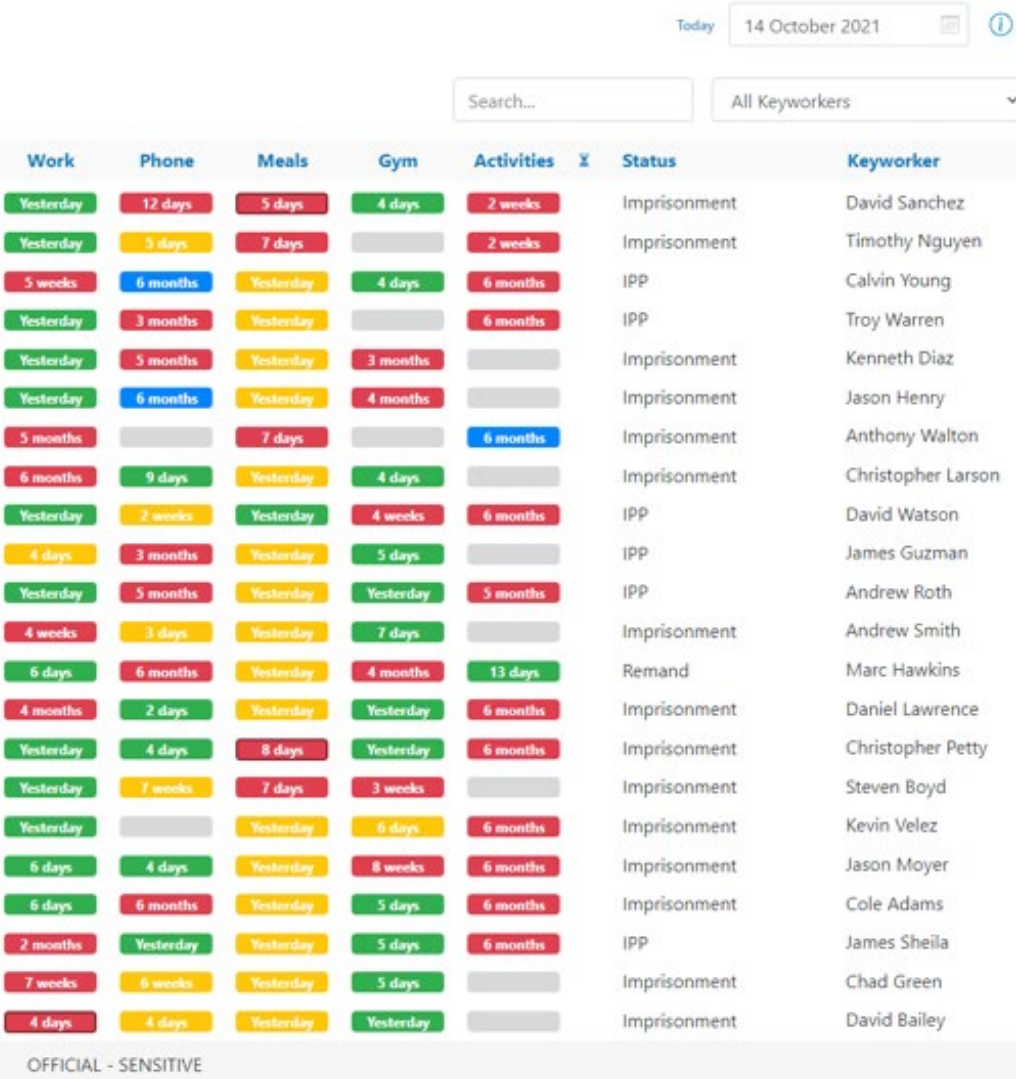

Figure 1 - Vulnerability Predictor Tool Main Operational Dashboard ${ }^{1}$

\footnotetext{
${ }^{1}$ Figure 1 - Vulnerability Predictor Tool Main Operational Dashboard
} 
The Vulnerability Predictor is a web application developed by Unilink with the purpose of identifying prisoners who are isolated, withdrawing from their regular routine and therefore potentially at a higher risk of selfinjurious or suicidal behaviours. It is helpful at a time when staff shortages have been exacerbated by Covid-19 and prisons have turned to less familiar or inexperienced staff to cover. The tool analyses data held on visits, work assignments, and other purposeful activities, and then displays the findings in such a way as to highlight behaviours changes and increased concern. The tool determines each resident's pattern of behaviour by undertaking a baseline from a predefined period of time. Any future marked decrease in activity in the different domains results in an increased level of concern regarding their vulnerability. The levels are represented as follows:

- Green - within normal pattern

- Amber - slight decrease

- Red - concern

When there are three or more red areas of concern identified, the prisoner will show on a 'Targeted' list and the tool will also highlight recent changes and other factors like remand status, sentence type, cell/wing, keyworker and time spent in custody. Furthermore, users can assess all prisoners, search for common characteristics, and importantly drill down into each specific prisoners record to view interactions across different periods of time or focus in on the different domains across their prison history to look for patterns.

\section{Vulnerability Predictor}
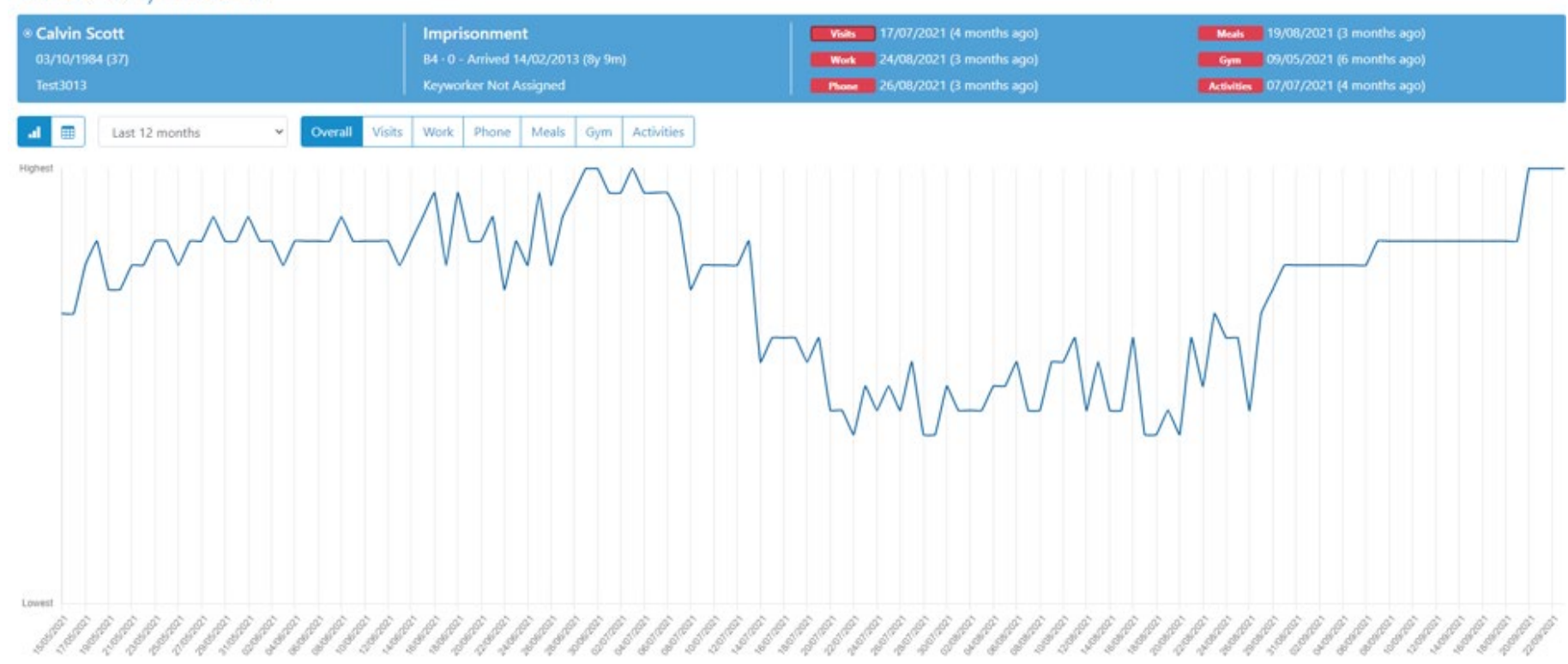

Figure 2 - Vulnerability Predictor Tool Prisoner Dashboard 
The data are refreshed daily, and the tool is underpinned by an algorithm that can be configured to fit the different characteristics of the prison and tailored to the needs of the prison's population Unilink plans to develop the tool further and aim towards what Favril et al. describes as:

"the contribution of both individual and environmental risk factors to self-harm in prison" in that "prisoners might import a vulnerability for self-harm into prison that might interact with custody-specific stressors, thereby increase the likelihood of self-harming in prison"

(Favril et al., 2020)

Thus, the tool has been designed as part of a whole-prison approach and multiagency collaboration towards the prevention of suicide and self-harm. It is provided as an additional tool which provides staff with a more analytical lens from which they can identify patterns of vulnerability and hopefully seek to protect the lives of those in prison - it is not a panacea for reducing suicide and self-harm, but an important part of a holistic approach to identifying at-risk prisoners and supporting them to be safe.

\section{References}

Favril, L., Yu, R., Hawton, K. and Fazel, S. (2020) Risk factors for self-harm in prison: a systematic review and meta-analysis Lancet Psychiatry, 7(8), pp. 682-691

Metzner, JL, \& Fellner, J. (2010). Solitary confinement and mental illness in U.S. prisons: A challenge for medical ethics. Journal of the American Academy of Psychiatry and the Law, 38(1), 104.

Ministry of Justice (2020). Safety in Custody Statistics, England and Wales: Deaths in Prison Custody to June 2020 Assaults and Self-harm to March 2020: Ministry of Justice. Available at: www.gov.uk/government/ collections/safety-in-custody-statistics 